\title{
Cartilha educativa para pescadores artesanais: produto educacional elaborado no Instituto Federal de Educação, Ciência e Tecnologia do Ceará (Brasil)
}

\author{
Educational booklet for artisanal fishermen: educational product prepared at the Federal Institute \\ of Education, Science and Technology of Ceará (Brazil) \\ Folleto educativo para pescadores artesanales: producto educativo elaborado en el Instituto \\ Federal de Educación, Ciencia y Tecnología de Ceará (Brasil)
}

Recebido: 08/11/2021 | Revisado: 17/11/2021 | Aceito: 30/11/2021 | Publicado: 11/12/2021

Valdo Sousa da Silva
ORCID: https://orcid.org/0000-0002-6755-3414
Instituto Federal de Educação, Ciência e Tecnologia do Ceará, Brasil
E-mail: silva.souza@ ifce.edu.br
Francisco das Chagas Silva Souza
ORCID: https://orcid.org/0000-0002-9721-9812
Instituto Federal de Educação, Ciência e Tecnologia do Rio Grande do Norte, Brasil
E-mail: chagas.souza@ifrn.edu.br

\begin{abstract}
Resumo
Este artigo resulta de uma pesquisa-ação desenvolvida no Mestrado Profissional em Educação Profissional e Tecnológica (ProfEPT), no Instituto Federal de Educação, Ciência e Tecnologia do Rio Grande do Norte, Campus Mossoró, e tem como objetivo relatar uma aproximação entre uma comunidade de pescadores artesanais e os docentes e técnicos do Curso Técnico Subsequente em Pesca do Instituto Federal de Educação, Ciência e Tecnologia do Ceará (IFCE), campus Acaraú, com fins de proporcionar uma troca de conhecimentos entre esses dois públicos. O projeto se desenvolveu, inicialmente, com uma pesquisa de campo no distrito do Guriú, em Camocim-CE, onde se encontra uma comunidade de pescadores artesanais. Em face da pandemia de Covid-19 e o distanciamento social, o desenvolvimento da pesquisa se deu a distância, com entrevistas focalizadas e registros de vídeos feitos pelos próprios pescadores com o uso dos seus aparelhos celulares. Os vídeos e as imagens fotográficas deram origem a um documentário observativo que foi apresentado aos professores e técnicos do Curso Técnico Subsequente em Pesca do IFCE, campus Acaraú. As discussões e sugestões dadas pelos docentes em duas rodas de conversas deram origem a cartilha com informações sobre legislação, segurança, associativismo e cuidados necessários na venda do pescado.
\end{abstract}

Palavras-chave: Comunidade tradicional; Documentário; Pesca artesanal; Pesquisa-ação; Produto educacional.

\begin{abstract}
This article is the result of a research carried out at the Mestrado Profissional em Educação Profissional e Tecnológica (ProfEPT), in the Instituto Federal de Educação, Ciência e Tecnologia do Rio Grande do Norte, Campus Mossoró. Its objective is to reflect on the process of rapprochement between a community of artisanal fishermen and the teachers and technicians of the Curso Técnico Subsequente em Pesca do Instituto Federal de Educação, Ciência e Tecnologia do Ceará (IFCE), campus Acaraú. The project began as a field investigation in the district of Guriú, in Camocim-CE, where the community of artisanal fishermen is located. However, in the face of the Covid-19 pandemic and social isolation, the development of the investigation continued remotely with interviews and records of videos made by the fishermen themselves with the use of cell phones. The videos and photographic images produced a documentary that was presented to the professors and technicians of the Subsequente em Pesca del IFCE, campus Acaraú. The discussions and suggestions offered by the teachers in two rounds of conversations gave rise to a booklet with information about legislation, safety, associativism and the necessary care in the sale of fish.
\end{abstract}

Keywords: Traditional community; Documentary film; Artisanal fishing; Investigation action; Educational product.

\section{Resumen}

Este artículo es el resultado de una investigación-acción desarrollada en el Mestrado Profissional en Educação Profissional e Tecnológica (ProfEPT), del Instituto Federal de Educação, Ciência e Tecnologia do Rio Grande do Norte, Campus Mossoró. Tiene como objetivo relatar la aproximación entre una comunidad de pescadores artesanales y los docentes y técnicos del Curso Técnico Subsequente em Pesca do Instituto Federal de Educação, Ciência e Tecnologia do Ceará (IFCE), campus Acaraú, para proporcionar un intercambio de conocimientos entre esos dos públicos. El proyecto comenzó como una investigación de campo en el distrito do Guriú, em Camocim-CE, donde se encuentra la comunidad de pescadores artesanales. No obstante, frente a la pandemia de Covid-19 y el aislamiento social, el desarrollo de la investigación continuó a distancia con entrevistas y registros de vídeos hechos por los 
mismos pescadores con el uso de celulares. Los vídeos y las imágenes fotográficas originaron un documental que fue presentado a los profesores y técnicos del Técnico Subsequente em Pesca del IFCE, campus Acaraú. Las discusiones $\mathrm{y}$ las sugerencias ofrecidas por los docentes en dos ruedas de conversaciones originaron una cartilla con informaciones sobre legislación, seguridad, asociativismo y cuidados necesarios en la venta del pescado.

Palabras clave: Comunidad tradicional; Documental; Pesca artesanal; Investigación-acción; Producto educativo.

\section{Introdução}

Uma análise da configuração da educação formal brasileira nos leva a constatar que, apesar de ter havido inúmeros avanços para a democratização do acesso às salas de aula, ainda é preciso evoluir bastante, principalmente em projetos afirmativos voltados às comunidades tradicionais.

Morin (2013) nos leva a refletir que, em tempos de grandes revoluções tecnológicas, é preciso conhecer e preservar os saberes dos povos tradicionais; saberes estes construídos pela experiência, mas que não deixam de existir enquanto ferramentas primárias importantes ao desenvolvimento do conhecimento científico-tecnológico.

Nessa perspectiva, é importante conhecer a realidade dessas populações e o trabalho que realizam coletivamente, com o propósito de desenvolver diálogos construtivos e capazes de produzir conhecimentos significativos, tanto para essas comunidades quanto para os pesquisadores, geralmente, presos aos espaços acadêmicos. Isso explica a relevância de apresentar ao público da Rede Federal de Educação Profissional, Científica e Tecnológica (docentes e discentes) as culturas tradicionais que muitos não conhecem ou, quando conhecem, às vezes os veem pela ótica dominante: povos estranhos, exóticos e de cultura inferior (Souza \& Silva, 2021, p. 24). Nessa direção, Lima et al (2020) observam que:

Unir a diversidade de culturas, saberes e pessoas de diferentes níveis socioeconômicos em um único espaço para se construir um conhecimento multiepistêmico é um grande desafio para a Universidade, principalmente a brasileira. Criada conforme o modelo de escolas europeias do século XIX, especificamente as escolas francesas e alemãs, e tendo como pressuposto monoepistêmico a ciência moderna ocidental, essa universidade formou exclusivamente, por pelo menos um século, a elite branca do Brasil. (p. 4).

Como exemplo dessa proposta, este artigo visa apresentar uma experiência de pesquisa realizada com um grupo de pescadores artesanais do distrito de Guriú, do município de Camocim-CE, e professores do Curso Técnico Subsequente em Pesca do Instituto Federal de Educação, Ciência e Tecnologia do Ceará (IFCE), campus Acaraú, a qual resultou em uma cartilha informativa para os pescadores que trabalham com esse tipo de pesca.

O Guriú foi criado por ato administrativo em 11 de fevereiro de 1890 e se destaca como o distrito mais antigo do município de Camocim-CE, que havia sido elevado à condição de cidade pela Lei Provincial no 2.162, de 17 de agosto de 1889 (Instituto Brasileiro de Geografia e Estatística [IBGE], 2017). Essa região, como grande parte das comunidades praianas no Brasil, é constituída por pequenas comunidades, cercadas por praias e manguezais, tendo basicamente a economia voltada à atividade pesqueira.

No que se refere à pesca, o distrito de Guriú tem seus pescadores organizados sindicatos, colônias e associações de modo a dar um suporte à prática da pesca artesanal e/ou de subsistência como no caso dos marisqueiros e marisqueiras, muito comuns na região. No Guriú, existem dois núcleos de organização comunitária de trabalhadores, uma representada pela Associação Comunitária de Moradores e outra pela Colônia de Pesca e Aquicultura de Camocim, sede regional.

Após realizarmos algumas visitas e fazermos contatos com a comunidade de pescadores do Guriú, percebemos que ali só se dispõe de uma escola de ensino fundamental, ou seja, esse distrito configura-se como muitas localidades brasileiras relegadas ao descaso com a educação de nível médio, técnico e superior. Porém, como um contraponto às lacunas estruturais na oferta de uma educação de qualidade, encontramos, a 70 km do Guriú, um Campus do IFCE, no município de Acaraú, que oferta cursos de licenciaturas e técnicos subsequentes ao ensino médio, dentre eles o curso Pesca. 
Diante dessa realidade, resolvemos desenvolver uma pesquisa que possibilitasse uma aproximação entre a comunidade de pescadores e os docentes e técnicos do Curso Técnico Subsequente em Pesca do IFCE, campus Acaraú, proporcionando uma troca de conhecimentos, um tipo de atividade que tem ocorrido em vários espaços acadêmicos, como destacaram Souza e Silva (2021). Ademais, desse encontro de saberes resultaria o produto educacional necessário à conclusão do Mestrado Profissional em Educação Profissional e Tecnológica (ProfEPT) no Instituto Federal de Educação, Ciência e Tecnologia do Rio Grande do Norte, Campus Mossoró.

De acordo com o Documento da Área de Ensino da Coordenação de Aperfeiçoamento de Pessoal de Nível Superior (Capes), Esse produto pode ser, por exemplo, uma sequência didática, um aplicativo computacional, um jogo, um vídeo, um conjunto de vídeo-aulas, um equipamento, uma exposição, entre outros. A dissertação/tese deve ser uma reflexão sobre a elaboração e aplicação do produto educacional respaldado no referencial teórico metodológico escolhido (Brasil, 2019, p. 15).

O produto educacional, que caracteriza o Mestrado Profissional em Ensino, também o diferencia do Mestrado Acadêmico, "uma vez que não tem como pressuposto a pesquisa, nem formar pesquisadores, apesar da pesquisa integrar a etapa de construção do produto". (Pasqualli et al., 2018, p. 110).

Assim, como resultado da nossa pesquisa, foi criada uma cartilha informativa para os pescadores, visto que muitos trabalhadores da pesca, nessa região, possuem baixo grau de estudos e pouca oportunidade ao aprimoramento de conhecimentos técnico-científicos. Na cartilha tratamos de informações acerca da segurança, qualidade e produtividade no trabalho que desenvolvem apenas com os conhecimentos tradicionais repassados através de seus antepassados.

\section{Metodologia}

O contato entre os pescadores artesanais e os professores e técnicos do Curso de Pesca do IFCE estava previsto para acontecer presencialmente, com uma visita dos pescadores àquela instituição. No entanto, antes disso, fizemos algumas visitas à comunidade para melhor conhecer e aplicamos um formulário com questões abertas e fechadas, com a finalidade de levantar informações socioeconômicas e acerca do cotidiano daquelas famílias.

O formulário, definido por Gil (2002, p. 115), como "a técnica de coleta de dados em que o pesquisador formula questões previamente elaboradas e anota as respostas", foi a técnica que melhor se adequou à pesquisa de campo pois muitos pescadores têm baixo nível de instrução e teriam dificuldades em responder questionários. Além disso, fizemos vários registros fotográficos da região, dos instrumentos de trabalho dos pescadores e do retorno de alguns barcos da pescaria. Nosso interesse pelas imagens se deu porque estas oferecem, conforme afirma Loizos (2002, p. 137) "um registro restrito, mas poderoso das ações temporais e dos acontecimentos reais - concretos, materiais. Isto e verdade tanto sendo uma fotografia produzida quimicamente ou eletronicamente, uma fotografia única, ou imagens em movimento". Contudo, esse autor salienta que as imagens podem ser manipuladas e alerta que a frase "a câmera não pode mentir" é uma falácia.

Destacamos que todos os passos da pesquisa foram descritos no projeto submetido ao Comitê de Ética em Pesquisa (CEP) e só foram realizadas após aprovado por esse comitê. Dessa forma, todas as pessoas envolvidas na pesquisa, pescadores e docentes, assinaram um Termo de Consentimento Livre e Esclarecido (TCLE), da mesma forma a gestão do Campus Acaraú.

Entretanto, a pesquisa in loco foi interrompida por alguns meses em função da pandemia da covid-19 e a necessidade de afastamento social. Como nova estratégia para prosseguir na investigação, solicitamos e orientamos os pescadores, por vídeo e áudios, que eles fizessem, com os seus aparelhos celulares, pequenos vídeos se apresentando, falando sobre o seu trabalho e exercendo-o. Também foram realizadas entrevistas, pelo celular, com 9 pescadores; nestas entrevistas, eles ficaram livres para narrar suas experiências de vida, afinal, "Contar histórias implica estados intencionais que aliviam, ou ao menos tornam familiares, acontecimentos e sentimentos que confrontam a vida cotidiana normal” (Jovchelovitch \& Bauer, 2002, p. 91). 
Como afirma Gil (1999), a entrevista é uma forma de interação social "bastante adequada para obtenção de informações acerca do que as pessoas sabem, creem, esperam, sentem ou desejam" (p. 117). As entrevistas foram de tipo focalizadas, nas quais "o entrevistador permite ao entrevistado falar livremente sobre o assunto, mas, quando este se desvia do tema original, esforça-se para a sua retomada" (Gil, 1999, p. 120). Além de Gil (1999, 2002), outros autores como Szymanski (2011) e Quaresma e Bini (2005) nos orientaram sobre como proceder nesses contatos.

Os vários vídeos produzidos, juntamente com as fotografias feitas por nós e por alguns pescadores, foram utilizados na produção de um documentário de modo observativo, que, segundo Nichols (2005, p. 62) "enfatiza o engajamento direto no cotidiano das pessoas que representam o tema do cineasta, conforme são observadas por uma câmera discreta". Nesse tipo de documentário, o cineasta somente observa os acontecimentos em seu transcorrer, sem interferências. Porém, por se tratar de um produto educacional de um Programa de Pós-Graduação e que ficaria disponibilizado na plataforma Educapes, tivemos que fazer uma abertura explicando do que se tratava o documentário e a sua finalidade, como também expor os nomes dos entrevistados.

O segundo momento da pesquisa se deu com os professores e técnicos do Curso Técnico Subsequente em Pesca do IFRN/Acaraú. Na impossibilidade de promover um encontro presencial entre os pescadores e os professores e técnicos, aproveitamos o espaço de uma reunião virtual do colegiado do referido curso e convidamos todos os presentes para a participação de dois encontros virtuais sobre o trabalho que realizamos na comunidade de Guriú. Todos os professores e técnicos aceitaram o convite e assinaram o TCLE. Foram então marcadas duas rodas de conversas que ocorreram com a presença de 06 professores e 02 técnicos. A opção pelas rodas de conversa se deu por serem ferramentas para discussões reflexivas utilizadas nas metodologias participativas (Afonso \& Abade, 2008). Iervolino e Pelicioni (2001) salienta que uma discussão em grupo deve sempre proporcionar descontração para que os participantes respondam questões em conjunto, em vez de individualmente.

As rodas de conversa lembram os "Círculos de cultura", como denominava Freire (1998), uma forma de utilizar-se o diálogo para o processo de ler o mundo, problematizá-lo, compreendê-lo e transformá-lo. Para Freire (1998) construir conhecimento reflexivo por meio de interação de conversas:

Não é dizer-se descomprometidamente dialógico; é vivenciar o diálogo. Ser dialógico é não invadir, é não manipular, é não organizar. Ser dialógico é empenhar-se na transformação constante da realidade. Esta é a razão pela qual, sendo o diálogo o conteúdo da forma de ser própria à existência humana, está excluído de toda relação na qual alguns homens sejam transformados em "seres para outro" por homens que são falsos "seres para si".

Tendo o aceite formal dos docentes e técnicos, com as devidas anuências de TCLE quanto ao uso de imagem e gravação de voz e das reuniões, agendamos os dias para os encontros e elaboramos as perguntas desencadeadoras para gerar discussões, ideias e contribuições a partir da exibição do documentário.

Em face do exposto, esse estudo, cujo objetivo era suscitar uma discussão entre os conhecimentos tradicionais dos pescadores artesanais da comunidade do Guriú e os conhecimentos acadêmicos dos professores do Curso Técnico Subsequente em Pesca, gerando um produto educacional, pode ser caracterizada como uma pesquisa-ação, assim definida por Thiollent (1986): A pesquisa-ação é um tipo de pesquisa social com base empírica que é concebida e realizada em estreita associação com urna ação ou com a resolução de um problema coletivo e no qual os pesquisadores e os participantes representativos da situação ou do problema estão envolvidos de modo cooperativo ou participativo. (p. 14)

Para esse autor, a pesquisa-ação consiste no relacionamento desses dois tipos de objetivos: um prático, "contribuir para o melhor equacionamento possível do problema considerado como central na pesquisa, com levantamento de soluções e proposta de ações correspondentes às 'soluções' para auxiliar o agente (ou ator) na sua atividade transformadora da situação"; 
e um objetivo de conhecimento: "obter informações que seriam de difícil acesso por meio de outros procedimentos, aumentar nosso conhecimento de determinadas situações (reivindicações, representações, capacidades de ação ou de mobilização, etc.)" (Thiollent, 1986, p. 18).

Portanto, a pesquisa tem caráter qualitativo, uma vez que, para Bogdan e Biklen (1994), possui 5 características: a fonte direta dos dados é o ambiente natural; é descritiva; interessa-se mais com o processo do que com os resultados; a análise dos dados se dá de forma indutiva; o significado tem importância vital. Creswell (2007), acrescenta que as investigações qualitativas usam métodos múltiplos que são interativos e humanísticos; é emergente em vez de estritamente pré-configurada; é fundamentalmente interpretativa; o pesquisador qualitativo reflete sistematicamente sobre quem é ele na investigação e é sensível à sua biografia pessoal e à maneira como ela molda o estudo; o investigador adota e usa uma ou mais estratégias de investigação corno um guia para os procedimentos no estudo qualitativo.

\section{Resultados e Discussão}

Foram realizadas 2 rodas de conversas no mês de abril de 2021. O primeiro encontro ocorreu com a presença de 4 professores e 2 técnicos. $\mathrm{O}$ segundo encontro aconteceu com a presença de mais 2 professores que não puderam comparecer ao primeiro dia de debate, contudo, um professor que participou do primeiro encontro não conseguiu comparecer ao segundo, o que representa 7 participações no segundo encontro com 8 participantes no geral. Os encontros tiveram duração média aproximada de 2 horas.

Para tornar o primeiro encontro objetivo e acessível a todos os participantes, uma vez que estes possuem uma carga horária de trabalho bastante acentuada, foi disponibilizado o link do arquivo contendo o documentário, com alguns dias de antecedência. A reunião teve início com reflexões trazidas com perguntas desencadeadoras e relacionadas ao objetivo da pesquisa. Esses questionamentos, segundo Szymanski (2011. p. 29), são “o ponto de partida para o início da fala dos participantes, focalizando o ponto que se quer estudar e, ao mesmo tempo, ampliando o suficiente para que ele escolha por onde quer começar".

Em se tratando da utilização de perguntas desencadeadoras para o debate de um assunto, há vários critérios a serem considerados, tais como:

a- $\quad$ a consideração dos objetivos da pesquisa;

b- a amplitude da questão, de forma a permitir o desvelamento de informações pertinentes ao tema que se estuda;

c- o cuidado de evitar a indução de resposta;

d- a escolha dos termos da pergunta, que deverão fazer parte do universo linguístico do participante;

e- a escolha do termo interrogativo [...] (Szymanski, 2011, p. 31).

Seguindo e proposição de um encontro descontraído, as primeiras perguntas do processo de debate foram referentes à formação individual de cada professor, perfil dos seus alunos e se encontram dificuldades no processo de ensinoaprendizagem. Essas primeiras indagações foram pertinentes à identificação do nível de formação acadêmica de cada professor, ligação destes com o curso e suas percepções quanto às dificuldades apresentadas pelos alunos em relação às suas práticas. Também questionamos a respeito da semelhança ou não entre os seus alunos e os pescadores do Guriú. O objetivo era saber o que aqueles docentes sabiam a respeito dos conhecimentos tradicionais da pesca artesanal e se esses saberes chegam à escola.

Concluído o primeiro encontro, foi possível perceber que os professores participantes possuíam alto grau de formação acadêmica, alguns com título de doutorado, e ministram disciplinas relacionadas à proposta curricular para formação do Técnico em Pesca. Quanto aos técnicos, os dois que participaram da pesquisa atuam no apoio em sala de aula e laboratórios, 
todos possuem de nível superior e um deles tem mestrado. Em relação ao perfil dos alunos e à dificuldade destes com o processo de ensino-aprendizagem, todos os professores demonstraram estar atentos às características dos discentes e aos principais entraves no processo de aprendizagem, que é o déficit na formação propedêutica, uma vez que a modalidade subsequente apresenta sérios problemas com a formação do ensino médio trazidos pelos alunos. Todos os professores e técnicos presentes reconheceram semelhanças culturais entre os pescadores do documentário e os alunos do curso técnico, entretanto, apontaram diferenças quanto à idade do público a ser comparado.

Considerando que se tratava de uma pesquisa-ação e que esta visa superar a lacuna entre teoria e prática, ou seja, intervém-se na prática já no decorrer da pesquisa e não apenas como uma recomendação no fim do estudo (Engel, 2000, Stake 2011, Thiollent, 1986, Tripp, 2005), solicitamos, aos participantes, uma análise do documentário e apontamentos de suas áreas de atuação, como uma forma de contribuir para a construção de uma cartilha educativa para os pescadores artesanais. Este foi o tema do segundo encontro, que teve como finalidade reverberar ações positivas, inovadoras e transformadoras para as comunidades que se ocupam da pesca artesanal não apenas no Guriú. Assim, seguir-se-ia as orientações de Dionne (2007): "o objetivo primeiro da pesquisa-ação é mudar uma dada situação particular levando em consideração a totalidade concreta tal como é vivida. Se não fosse assim, por que se falar em pesquisa-ação? Bastaria a pesquisa aplicada clássica”. (p. 23)

O segundo encontro ocorreu uma semana após o primeiro. Na oportunidade, professores e técnicos do Curso Técnico Subsequente em Pesca do IFCE/Acaraú contribuíram com as comunidades de pescadores artesanais, mediante orientações técnicas que, segundo a legislação brasileira, devem ser seguidas para a segurança e melhor desenvolvimento das atividades pesqueiras. As instruções técnicas que deram origem a uma cartilha foram agrupadas em três grupos temáticos, a saber: legislação pesqueira, normas técnicas para o trabalho do pescador e preservação ambiental na perspectiva do desenvolvimento sustentável de comunidades tradicionais.

Alguns professores que trabalham com atividades de campo relataram que tentam, de toda forma, uma aproximação com as comunidades de pescadores locais, principalmente para fornece-lhes informações necessárias ao cumprimento de normas e procedimentos técnicos que só teriam a contribuir para as suas condições de trabalho. Contudo, segundo esses professores, existem barreiras culturais entre os conhecimentos da tradição e as orientações técnico-cientificas que o curso de pesca do IFCE, campus de Acaraú, se prontifica a oferecer as comunidades pescadoras locais, ou seja, grande parte das comunidades desses pescadores se mostra relutante em aceitar as orientações técnicas, vistas, algumas vezes, com desconfiança e desprezo.

Reportemos alguns comentários dos professores e técnicos participantes desse segundo encontro. Para que sejam resguardadas as identidades dos profissionais da educação técnica, aqui consideraremos todos como professor, no masculino, ao invés de mencionar os nomes próprios e cargo de cada participante. O primeiro deles falou da importância da conservação do pescado, dizendo que não visualizou no documentário nenhum tipo de cuidado com a conservação do peixe dentro da embarcação. Frisou que, para a comercialização de um produto de qualidade, são necessárias algumas providências quanto ao congelamento e armazenamento do pescado, pois isso agregaria valor e qualidade ao produto. A respeito dessas observações, o professor comenta:

Outra coisa que eu vi, que é característico da maioria das comunidades pesqueiras do Brasil, e lá no Guriú não é diferente, é que eles carecem de um local adequando para o armazenamento e beneficiamento do pescado, que é uma coisa de fundamental importância para a comunidade, que eles possam ter um local, entreposto, com o mínimo de condições para que esse pescado tenha qualidade e que eles aumentem o preço do quilo na venda do mesmo. Para isso a comunidade necessita de treinamento no manejo a bordo. O pescador precisa entender que quanto maior a qualidade do pescado maior será o preço do quilo que ele poderá vender ${ }^{l}$.

${ }^{1}$ Usamos itálico para distinguir os relatos dos docentes das citações diretas. 
Outra importante observação desse professor é sobre a preservação ambiental relacionada às atividades da pesca artesanal:

A outra coisa que eu vejo que é fundamental é a parte da conscientização ambiental, eles terem nessa cartilha, acho que é fundamental para as espécies que eles exploram. É importante eles saberem quais as espécies que estão ameaçadas, qual é o tamanho mínimo para cada espécie que eles capturam e o porquê que existe isso, para a proteção e conservação da espécie, eles sabem que existe aparelho de pesca legal e ilegal para determinado recurso. Se tem alguém nessa comunidade que utiliza aparelhos de pesca ilegal, não é o tom de punição, é só mostrar as consequências do uso da pesca ilegal.

Finalizando sua fala, o professor tece contribuição quanto à importância de os pescadores artesanais conhecerem a legislação de suas atividades laborais, pois é nesta que estão os direitos e deveres.

Deixar claro para eles qual é a diferença da identidade deles enquanto pescador que é o RGP (Registro Geral de Atividade Pesqueira), que hoje é emitido pela SAP - Secretaria de Aquicultura e Pesca, e os cursos de formação do ensino profissional marítimo da marinha que eles podem fazer. É bom eles se entenderem também quais os tipos de documentações que eles precisam ter para desenvolverem as atividades deles da melhor forma possível, lembrando que pescador hoje é uma profissão regulamentada, eles podem se aposentar como pescador, e eles terem todas as documentações é de fundamental importância para esse momento, estarem filiados a colônia e entenderam a importância da colônia de pesca que é a representação dele junto aos seus direitos. Direitos e deveres.

Outro professor complementa as observações feitas pelo primeiro e lembra que nem sempre a extinção das espécies está ligada à super exploração desta, mas também a uma degradação do meio ambiente. Expôs que conhece a região do Guriú e comentou sobre a degradação dos manguezais nesta localidade, que sofre com atividades turísticas, principalmente em áreas onde se localizam espécies de cavalos marinhos. Quanto a essas observações, o professor argumenta:

Saiu esse ano uma estimativa da Fundação Boticário, que, pelo menos $50 \%$ da pesca artesanal em alguns estados do Brasil, têm ligações diretas com área de manguezal, e até $80 \%$ das espécies que são pescadas comercialmente, que são espécies marinhas, se reproduzem, se alimentam ou encontram abrigo dentro dos manguezais. Então, a minha sugestão é que a gente inclua nessa cartilha algo sobre a preservação desses ambientes, já que esses locais possuem uma grande função para a continuidade das atividades pesqueira no futuro.

O terceiro professor a se manifestar reforçou os cuidados com o peixe capturado, disse ser fundamental reforçar, para os pescadores, a importância da conservação do pescado após a captura, sendo preciso realizar cursos de formação nesse segmento. Salientou também a necessidade da utilização de equipamentos de segurança marítima, pois, segundo ele:

95\% de toda a pesca artesanal no Ceará tem problema de qualidade, problema na embarcação, problema na formação, problema na segurança, e aí tudo isso precisa não só de curso, pois todos que deram entrevista no documentário afirmam ter a CIS da marinha, mas existe a cultura de não colocar em pratica a questão da segurança, tanto é que lá no início do vídeo quando os rapazes irão pescar, eles mostram um colete, eles só mostraram o colete, botar o colete de jeito nenhum, vi lá o pescador colocando a linha no dedo do pé, eles não usam luvas, nada.

A participação do quarto professor vem também reforçar as colocações dos demais colegas sobre a necessidade de conscientização para o processo de conservação do pescado:

Acredito que eles tenham consciência da importância dessa conservação, mas não é visível no vídeo e não é só lá, como o professor apontou, não é um problema dessa comunidade em especifico, então esse é um ponto que precisa estar presente lá na cartilha. 
O mesmo professor corroborou com as palavras de um colega sobre a questão da necessidade do uso do colete que, no documentário, foi mostrado como um equipamento necessário a ser usado no mar, mas não foi utilizado em nenhum momento pelos pescadores durante o vídeo. Para esse professor, é notória a importância da utilização de equipamentos de segurança no mar, e isso, os pescadores: "sabem por que já fizeram o curso da marinha, por isso já lhes foi apontado essa importância, contudo, eles não demostraram esse cuidado mesmo sabendo que estaria gravando".

$\mathrm{O}$ quinto professor acrescentou observações sobre a ameaça ao espaço reprodutor de cultura e conhecimentos de comunidades de pescadores que se localizam em áreas de forte exploração turísticas e, dessa maneira, sugere formas de associações comunitárias que possam atrelar um turismo sustentável ao desenvolvimento da produção local de pescado e artesanato.

Com relação ao turismo, que parece que está chegando forte ali, eles poderiam estar agregando a questão da pesca com a questão do turismo, eles poderiam estar, por exemplo, agregando valor a esse pescado ao invés de vender para o atravessador toda a sua produção, vender através de um restaurante comunitário, para isso eles precisam se reunir, mas isso não é um processo simples, é uma vivência.

O próximo professor a manifestar sua opinião detalhou questões referentes à estrutura das canoas, embarcações de convés aberto, os pequenos barcos que os pescadores do documentário utilizam em seu ofício. Segundo o docente, embarcações de estrutura menores devem limitar-se a navegação até certa distância da costa, pois, caso contrário, corre o risco de naufrágio e outros acidentes referentes a avarias que podem ser causadas por um oceano revolto. Para isso, usa como argumento uma pesquisa que desenvolveu a respeito de informações sobre naufrágios na região do Acaraú.

os maiores naufrágios são das canoas, volta e meia se escuta uma notícia, disso, de virada, então tem muito disso, os maiores naufrágios são de pequenas embarcações, que começam alagar, começa chover, ou você pesca, ou você presta atenção ao movimento do mar, ou você tira água da canoa, então chega o momento que vai estar totalmente alagada, e o salva vidas serve pra isso.

Outro professor destacou a necessidade da utilização dos coletes salva vidas para a proteção de pescadores contra naufrágio e outros problemas que porventura possam ocorrer em meio ao oceano. Argumentou que muitos alunos que estudam no Curso Técnico Subsequente em Pesca não têm a mínima noção de práticas de natação, atividade importantíssima a quem deseja trabalhar embarcado. Sobre seus argumentos relata:

Eu os vi mostrando o colete, aí quando eu fui ver a cena deles no mar mesmo, o equipamento de segurança não aparecia, eu não sei como funciona essa questão da legislação, mas, pelo menos, um colete é obrigatório, pois acho que vocês sabem disso melhor do que eu, no mar não basta só saber nadar. Entre os alunos de pesca que fizeram educação física comigo, muitos não sabem o básico da natação, eu precisei fazer um trabalho especial com eles, muitos tinham até medo de submergir a cabeça na água, então isso daí pode ser um risco muito grande.

A partir desses comentários e sugestões, organizamos a "Cartilha informativa ao pescador artesanal", com linguagem fácil de compreensível a todo público de pessoas. A organização dessa cartilha visou proporcionar um encontro de saberes, no caso, um contato entre os professores e as comunidades de pescadores da região, uma vez que, pelo documentário observativo, estes últimos já tinham exercido seu lugar de fala mediante as experiências no Guriú.

Considerando, no processo de pesquisa, as dificuldades que muitos pescadores possuem para interpretar informações escritas, com texto padrão da língua portuguesa culta, a construção da "Cartilha informativa ao pescador artesanal" seguiu padrões iconográficos, transcodificando mensagens com poucos textos e mais imagens reais e/ou desenhos que pudessem transmitir as informações e orientações passadas pelos professores, porém, de forma mais rápida e eficiente ao público 
Research, Society and Development, v. 10, n. 16, e188101622991, 2021

(CC BY 4.0) | ISSN 2525-3409 | DOI: http://dx.doi.org/10.33448/rsd-v10i16.22991

específico. A cartilha possui 6 páginas, sendo as 2 últimas com maiores informações sobre o IFCE e o Curso Técnico Subsequente em Pesca. Mesmo que muitos pescadores adultos tenham dificuldades com leituras, essas informações sobre a instituição e os seus cursos são importantes para os mais jovens e adolescentes e podem despertar o interesse em ali seguir seus estudos e serem técnicos em pesca (Figura 1).

Figura 1 - Cartilha informativa ao pescador artesanal.
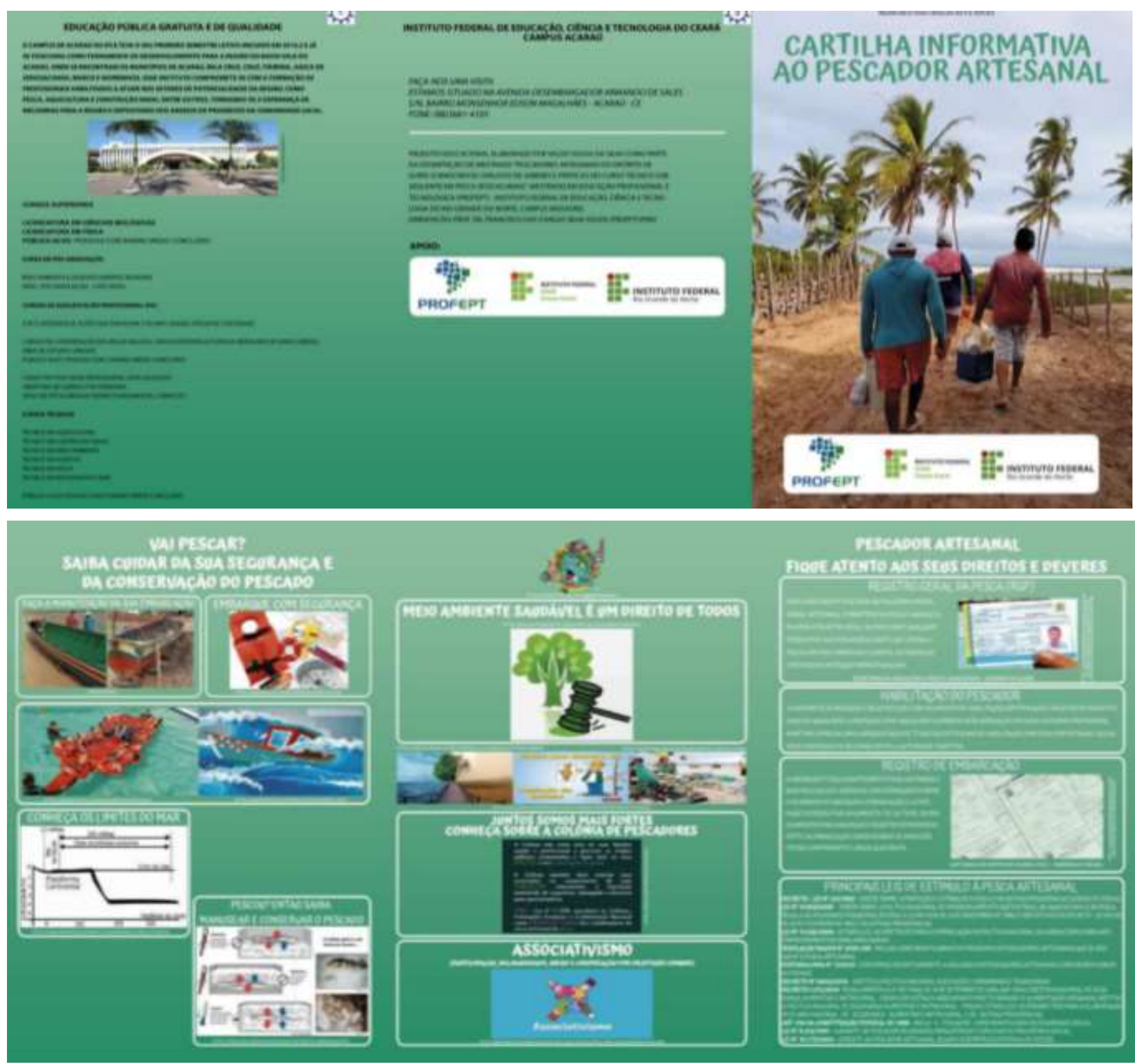

Fonte: Autores.

Conforme podemos perceber, referente às observações de legislação pesqueira, estão as orientações sobre a regulamentação das atividades na pesca artesanal, credenciais e cursos necessários para o exercício de atividades no mar, além de legislação sobre direitos e deveres do pescador artesanal, a exemplo: o direito ao seguro defeso, de associações, de aposentadoria etc. 
As observações de normas técnicas para o trabalho do pescador seguem as orientações para a utilização de equipamentos de proteção de segurança no mar, conservação dos barcos, limites em milhas para navegação conforme o tamanho das embarcações, técnica de manejo e conservação do pescado para o cumprimento das normas de segurança alimentar e qualidade de produção.

Quanto à preservação ambiental na perspectiva do desenvolvimento sustentável de comunidades tradicionais, orientou-se por uma conduta para a utilização de apetrechos de pesca que possam mitigar o risco da captura de espécies marinhas em extinção, e práticas de trabalho que eliminem o descarte de lixo no oceano e praias da região, além de orientações ao associativismo como uma proposta de desenvolvimento sustentável para comunidades tradicionais de pescadores.

Em face do exposto, é possível percebermos nas trocas de saberes, embora não tenham ocorrido conforme planejado em função da pandemia, momentos de reflexões sobre uma prática de trabalho mais voltada à sobrevivência do grupo de pescadores artesanais, experiências que foram e são passadas entre as gerações, uma realidade importante de ser vista numa sociedade na qual " $\mathrm{O}$ trabalho descaracteriza-se enquanto atividade ontológica, em que se produz em prol do valor de uso, e se próxima de atuações práticas e particularizadas, centradas na venda da força de trabalho - no valor de troca" (Santos \& Silva, 2020, p. 5).

\section{Considerações Finais}

A pesquisa aqui descrita deu-se a partir da finalidade de promovermos trocar de saberes por parte dos pecadores artesanais que, mediante o documentário, acreditamos terem contribuído para a formação continuada de professores e técnicos do Curso Técnico Subsequentes em Pesca do IFCE, Campus Acaraú, ao expor suas realidades e metodologias de trabalho, ou seja, os seus saberes que estão distante da escola; por sua vez, esses docentes, representantes da academia e dos conhecimentos científicos, contribuíram para o trabalho dos pescadores por meio de orientações técnicas importantes para a segurança, para a captura e venda do pescado e para o associativismo.

Consideramos que o nosso trabalho, como outros produzidos no ProfEPT/IFRN, em Mossoró, analisados por Souza et al (2020), contribuiu para a formação humana integral, em oposição à formação tecnicista para o mercado de trabalho, embora essa discussão não seja aprofundada nos currículos dos cursos técnicos na forma subsequente, que carecem de disciplinas na área das Ciências Humanas.

\section{Agradecimentos}

Agradecemos aos pescadores artesanais do distrito do Guriú, em Camocim-CE, e aos professores e técnicos do Curso Técnico Subsequente em Pesca do Instituto Federal de Educação, Ciência e Tecnologia do Ceará, pela receptividade em colaborar com a nossa pesquisa.

\section{Referências}

Afonso, M. L., \& Abade, F. L. (2008). Para reinventar as rodas: rodas de conversa em direitos humanos. Rede de Cidadania Mateus Afonso Medeiros. https://ufsj.edu.br/portal-repositorio/File/lapip/PARA_REINVENTAR_AS_RODAS.pdf

Bogdan, R., \& Biklen, S. (1994). Investigação qualitativa em educação: uma introdução à teoria e aos métodos. Porto Editorial.

Boni, V., \& Quaresma, S. J. (2003). Aprendendo a entrevistar: como fazer entrevistas em ciências sociais. Em tese, 2(1), 68-80. https://doi.org/10.5007/\%25x

Brasil, Coordenação de Aperfeiçoamento de Pessoal de Nível Superior. (2019). Documento de Área - Ensino.

Creswell, J. W. (2007). Projeto de pesquisa: métodos qualitativo, quantitativo e misto. (2a ed.). Artmed.

Dionne, H. (2007). A pesquisa-ação para o desenvolvimento local. Liber Livro.

Engel, G. I. Pesquisa-ação. Educar, 16, 181-191. 2000. https://revistas.ufpr.br/educar/article/view/2045 
Research, Society and Development, v. 10, n. 16, e188101622991, 2021

(CC BY 4.0) | ISSN 2525-3409 | DOI: http://dx.doi.org/10.33448/rsd-v10i16.22991

Freire, P. (1998). Pedagogia do oprimido (25a ed.). Paz e Terra.

Gil, A. C. (2002). Como elaborar projetos de pesquisa (4a ed.). Atlas.

Gil, A. C. (1999). Métodos e técnicas de pesquisa social (5a ed.). Atlas.

Iervolino, S. A.; Pelicioni, M. C. F. (2001). A utilização do grupo focal como metodologia qualitativa na promoção da saúde. Revista da Escola de Enfermagem da USP, 35(2). 115-121. https://www.scielo.br/j/reeusp/a/kFzCC9Dfbfv7WzPNQbJZVmF/?lang=pt\&format=pdf

Instituto Brasileiro de Geografia e Estatística. (2017). IBGE Cidades. https://cidades.ibge.gov.br/brasil/ce/camocim/historico

Jovchelovitch, S., \& Bauer, M. W. (2002). Entrevista narrativa. In M. W. Bauer \& G. Gaskell. (Eds). Pesquisa qualitativa com texto: imagem e som: um manual prático. (2a ed.), 90-113. Vozes.

Lima, H. F.; Amaral, J. A.; Sacramento, R. A. L.; \& Costa, E. F. (2020). Reflexões sobre o "Projeto Encontro de Saberes" enquanto experiência teóricometodológica pós-colonial e da Ecologia de Saberes no ensino superior. Research, Society and Development, 9(7), e650974525. http://dx.doi.org/10.33448/rsd-v9i7.4525

Loizos, P. (2002). Vídeos, filmes e fotografias como documentos de pesquisa. In: Bauer, M. W.; \& Gaskell, G. (Eds). Pesquisa qualitativa com texto: imagem e som: um manual prático. (2a ed.), 137-155. Vozes.

Morin, E. (2013). Os sete saberes necessários à educação do futuro. Cortez, UNESCO.

Nichols, B. (2005). Introdução ao documentário (5a ed.). Papirus.

Pasqualli, R., Vieira, J. A., \& Castaman, A. S. (2018). Produtos educacionais na formação do mestre em educação profissional e tecnológica. Educitec, 4(7), 106-120. http://dx.doi.org/10.31417/educitec.v4i07.302

Santos, D. V. N.; Silva, N. V. (2020). Pensando trabalho como princípio educativo e a educação não formal como bases para uma educação omnilateral. Research, Society and Development, 9(10), e5079108905. http://dx.doi.org/10.33448/rsd-v9i10.8905

Souza, F. C. S., Nunes, A. O., \& Oliveira, M. A. (2020). O Programa de Pós-Graduação em Educação Profissional e Tecnológica e a formação humana integral: análise da produção acadêmica no IFRN/Mossoró. Revista Brasileira da Educação Profissional e Tecnológica, 2. http://dx.doi.org/10.15628/rbept.2020.11629

Souza, F. C. S., \& Silva, V. S. (2021). Conhecimentos tradicionais versus conhecimentos científicos? em defesa de uma educação que religue os saberes. Educação Profissional e Tecnológica em Revista, 5(Especial), pp. 8-28. https://doi.org/10.36524/profept.v5iEspecial.1104

Stake, R. E. (2011). Pesquisa qualitativa: estudando como as coisas funcionam. Pensa.

Szymanski, H. (2011). A entrevista na educação: a prática reflexiva. (4a ed.). Liber Livro.

Thiollent, M. (1989). Metodologia da pesquisa-ação. Cortez, Autores Associados.

Tripp, D. (2005). Pesquisa-ação: uma introdução metodológica. Educação e Pesquisa. 31(3), 443-466. https://www.scielo.br/j/ep/a/3DkbXnqBQqyq5bV4TCL9NSH/?format=pdf\&lang=pt 